\title{
Intertemporal Market Devision: A Case of Alternating Monopoly
}

Citation for published version (APA):

Herings, P. J. J., Peeters, R. J. A. P., \& Schinkel, M. P. (2001). Intertemporal Market Devision: A Case of Alternating Monopoly. Maastricht University School of Business and Economics. METEOR Research Memorandum No. 021 https://doi.org/10.26481/umamet.2001021

Document status and date:

Published: 01/01/2001

DOI:

10.26481/umamet.2001021

Document Version:

Publisher's PDF, also known as Version of record

\section{Please check the document version of this publication:}

- A submitted manuscript is the version of the article upon submission and before peer-review. There can be important differences between the submitted version and the official published version of record.

People interested in the research are advised to contact the author for the final version of the publication, or visit the DOI to the publisher's website.

- The final author version and the galley proof are versions of the publication after peer review.

- The final published version features the final layout of the paper including the volume, issue and page numbers.

Link to publication

\footnotetext{
General rights rights.

- You may freely distribute the URL identifying the publication in the public portal. please follow below link for the End User Agreement:

www.umlib.nl/taverne-license

Take down policy

If you believe that this document breaches copyright please contact us at:

repository@maastrichtuniversity.nl

providing details and we will investigate your claim.
}

Copyright and moral rights for the publications made accessible in the public portal are retained by the authors and/or other copyright owners and it is a condition of accessing publications that users recognise and abide by the legal requirements associated with these

- Users may download and print one copy of any publication from the public portal for the purpose of private study or research.

- You may not further distribute the material or use it for any profit-making activity or commercial gain

If the publication is distributed under the terms of Article $25 \mathrm{fa}$ of the Dutch Copyright Act, indicated by the "Taverne" license above, 


\title{
Intertemporal Market Division A Case of Alternating Monopoly
}

\section{P. Jean-Jacques Herings Ronald Peeters Maarten Pieter Schinkel*}

November 2001

\begin{abstract}
In dynamic entry-and-exit models, common understanding is that potential entrants will enter into the market up to the point where all excess profits are eroded. Dominant incumbent positions are possible only under specific circumstances, such as the presence of substantial barriers to entry, or when incumbents can credibly threaten to punish rivals with losses upon entry. In this paper, we report on an equilibrium with market dominance that exists in a simple two-firm model that features neither entry barriers nor punishment strategies. This equilibrium induces an alternating monopoly - despite the fact that the model also sustains a Cournot duopoly. Even when initially both firms are active in the market, an alternating monopoly reveals itself rather quickly. Moreover, the alternating monopoly equilibrium Pareto dominates the Cournot equilibrium - as it is close to the cartel outcome.
\end{abstract}

JEL Classification Codes: C73, D43, L13.

Keywords: Dynamic Competition, Oligopolistic Competition, Stochastic Games, Monopoly.

\section{Introduction}

A central debate in industrial economics concerns the question whether the threat of potential competition disciplines already incumbent firms. The benchmark model is that of perfect contestability, definitely laid out in Baumol, Panzar and Willig (1982). The model predicts that, in the absence of sunk costs, potential competition is sufficient to guarantee pricing at marginal costs, even when the number of both incumbents and potential entrants is low. Traditionally, going back to Bain (1956), contributions that seek to negate

* Department of Economics, Universiteit Maastricht, P.O. box 616, 6200 MD, Maastricht, The Netherlands (corresponding author: P.J.J. Herings, e-mail: P.Herings@algec.unimaas.nl). We thank Franklin Fisher and Marco Haan for valuable comments to an earlier draft of this paper. 
this result, and instead show that stable positions of market power for incumbent firms are possible, rely on the presence of sunk costs to throw up barriers to entry.

In a more sophisticated argument, in Stiglitz (1981) and Dasgupta and Stiglitz (1988), Cournot competition on quantities among potential entrants that simultaneously make their entry decisions, serves as a form of 'outside' competition among the potential entrants that discourages entry for each one of them. This, in fact, fortifies the position of incumbent firms when the number of potential entrants increases. When entry is played as a mixed strategy, however, as in Dixit and Shapiro (1986), or when it is sequential, as in Vives (1988) and Waldman (1991), potential competition generally again increases actual competition and hence welfare.

In a literature that answered Selten's chain store paradox, see Selten (1978), credible deterrence of entry relies, e.g., on the presence of imperfect information that allows for building a reputation to fight entry. Also punishment strategies of various kinds can sustain dominant positions in repeated games of entry. Crucially, however, these latter results depend on the fact that the game is repeated ad infinitum. In all, therefore, it is fair to say that common perception is that potential competition helps actual competition.

In this paper, we report on a surprising result in the simplest possible dynamic model of competition with entry and exit. There are no sunk costs, hence no barriers to entry, incumbents are in Cournot competition, entry and exit decisions take the form of mixed strategies, and there is perfect and complete information. Moreover, we limit the analysis to Markov strategies, thereby ruling out punishment strategies. Despite its simple setup, the dynamic model suffers from the notorious problem with models that feature subsequent choice over an infinite but discrete time horizon: they tend to be analytically very hard, so that it is difficult to characterize all the equilibria of the game. Recent developments in computational algorithms designed for this type of games, however, allow us to study the model's equilibria in detail.

Whereas one would expect that the model will quickly display a long-run Cournot duopoly, we find a different type of equilibrium, in which the market is intertemporally shared between the two firms. When the firms coordinate on this equilibrium, the probability that this industry structure of alternating monopoly is observed converges quickly to one, for all reasonable discount factors. Moreover, this equilibrium Pareto-dominates the Cournot equilibrium. Both firms are able to obtain higher profits by dividing the market intertemporally between them. This provides an interesting alternative to geographical market division. It has, to the best of our knowledge, so far been overlooked in the literature, yet it potentially poses a threat to competitive markets, and as such it possibly is a subject of antitrust policy concern. 


\section{A Simple Dynamic Entry-and-Exit Model}

Consider the simplest of possible dynamic models of entry and exit. Two firms, producing with constant marginal costs $c$ and no fixed costs, intend to serve a market characterized by the a linear demand curve, such that the market price $p$ depends on the sum total produced $Q$, as

$$
p=a-b Q .
$$

For each firm, the decision to be active in the market comes up every period. That is, each firm decides each period that it is in the market first how much to produce, and second whether to remain in the market for another period or to exit. Each period it is out of the market it decides whether to enter in the next period or not. Firms take these decisions simultaneously and independently of one another, and they can randomize over their strategies. As a consequence, no firm can observe the decisions of the other. In the following, there are neither entry, nor exit costs.

At any given time, the industry structure is one of four possible structures: either both firms are active in the market, or neither of them-so that there is no production at all-or one firm is active and the other is not, or vice versa. Each transition from a given market structure to another from one period to the next depends on the simultaneous and independent decisions of the firms whether or not to be active for production in the next period. Consequently, this dynamic entry-and-exit model can be modeled as a stochastic game. $^{1}$

The most general strategy a firm can formulate to play this game is a behavior strategy. In that, each firm specifies for each period, each market structure at that period, and each history leading up to it with which probability to be active in production next period. To this end, it is assumed that in each period both firms know the history of the market structure up to and including the current structure, and that this is common knowledge. Furthermore, in formulating their behavior strategies, firms discount the future profits they foresee by a factor $\delta \in(0,1)$.

A Nash equilibrium for this model is a pair of behavior strategies, one for each firm, for which it holds that each firm's strategy is a best response to the strategic decision of its opponent. In the following, we concentrate on stationary equilibria, which are Nash equilibria in stationary strategies. These are behavior strategies that are history and time independent, so that at all times actions depend only on the current state. Notice that the state contains only information on the current market structure-which firm is in

\footnotetext{
1 Stochastic games were first introduced in Shapley (1953). A recent authorative text is the forthcoming Neyman and Sorin (2001).
} 
and which is out - and excludes any information on past behavior. As the two firms are really identical - except perhaps for their position in the market-we consider symmetric stationary equilibria. That is, a firm behaves in equilibrium as the other firm would, when their positions were reversed.

Several motivations for analyzing stationary equilibria in the set of Nash equilibria can be found in Maskin and Tirole (2001). Stationary strategies describe the simplest form of behavior that is consistent with rationality, enable a clean and unobstructed analysis of the influence of state variables, and substantially reduce the number of parameters so that they can be conveniently simulated. Furthermore, stationarity captures the idea that 'bygones are bygones' more completely than does the concept of subgame-perfect equilibrium. This latter motivation is of principal interest here: stationarity of the behavior strategies of the firms, coupled with our state space, excludes the possibility to punish the rival firm. Consequently, none of the results obtained below relies on any form of punishment strategies by construction.

In the simple dynamic model considered here, in which the decisions of rivals can not yet be observed when deciding on the production level, in equilibrium all active firms produce the static Cournot quantity. Hence, when there are $k$ firms active in the market (here, $k$ equals 1 or 2 ), each firm $k$ produces the static Cournot quantity given by

$$
q_{k}^{C}=\frac{(a-c)}{(k+1) b}
$$

and the instantaneous profit to each of the $k$ active firms is

$$
\pi_{k}^{C}=\frac{(a-c)^{2}}{(k+1)^{2} b}
$$

In Figure 1 this stochastic game is depicted, where it is assumed, without loss of generality, that the common factor in the instantaneous profits for all $k$ is unity. That is, $\frac{(a-c)^{2}}{b}=1$. This can simply be justified by the choice of units. A firm choosing the strategy 'in' will produce in the next period, and a firm choosing strategy 'out' will be out of production in the next period. The instantaneous profits of the firms are given by the tuple in the upper-left part of the cells. The lower-right part of the cell indicates the next state, reached with probability one- $(1,1)$ means for example both firms in, and $(0,1)$ firm 1 out, firm 2 in.

Stationary equilibria exist in the type of model here considered, as follows from Fink (1964), Takahashi (1964), and Sobel (1971). So far, however, it has turned out to be difficult to completely identify the set of stationary equilibria of stochastic games analytically, even of the simple type considered here. Recently, some progress towards this end has been 

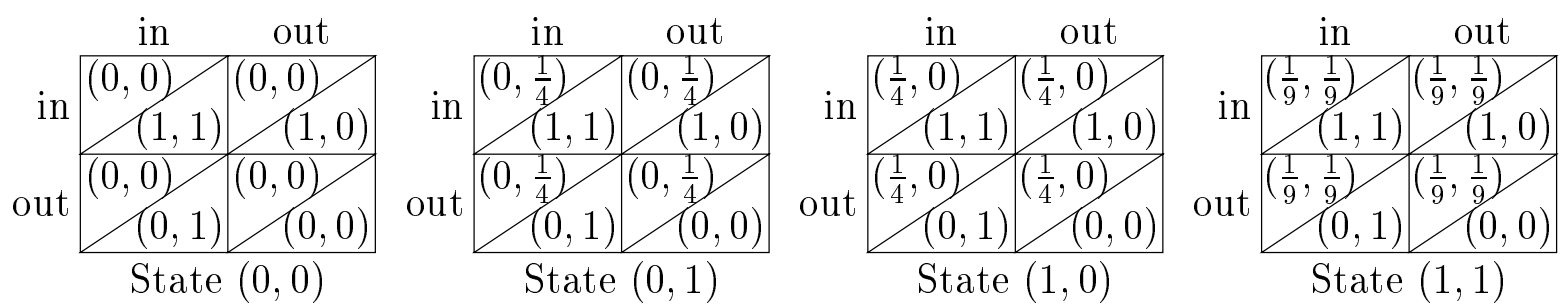

Figure 1: The dynamic entry-and exit model as a stochastic game.

made along a computational route, defended in Judd (1997) as an appropriate alternative where analytics fall short. The algorithm to compute stationary equilibria in stochastic games used in the following is developed in Herings and Peeters (2000). It is based on a system of polynomial (in)equalities given in an appendix to this paper. The algorithm converges almost surely. ${ }^{2}$ The appendix allows the reader to check the validity of our results.

One final note is in order here. As said, punishment strategies are absent in this model by contruction. As a consequence, the equilibrium results reported on below do not rely on the Folk Theorem. ${ }^{3}$ This is also reflected by the fact that the number of stationary equilibria in the type of model considered here is finite, as shown in Haller and Lagunoff (2000), and generically odd, as shown in Herings and Peeters (2000).

\section{Alternating Monopoly}

Conventional wisdom quickly leads to the claim that the market dynamics modeled above will typically result in the two firms sharing the market forever. After all, in the Cournot duopoly situation, there is a substantial profit over and above the entry costs - here assumed to be zero - for each firm. Moreover, there is no dynamic limit pricing-which would be fruitless in the absence of barriers to entry - nor do firms deploy punishment strategiesas they cannot by construction. And indeed it is the case that 'always stay when active' and 'always enter when not active'-or, alternatively, 'produce in the next period no matter what the current market structure is', is a (symmetric) stationary equilibrium.

Table 1 displays, for a discount factor $\delta=0.95$, these equilibrium strategies for each firm in each state, as well as the expected total discounted profits to the firms by coordinating

\footnotetext{
2 The algorithm belongs to the class of homotopy methods for which Judd (1998) is the standard reference. We have written a number of FORTRAN-subroutines to the software-package HOMPACK, a FORTRAN program to do homotopy-continuation calculations. Cf. Watson, Billups and Morgan (1987) and http://www.netlib.org/hompack/index.html.

$3 \quad C f$. Fudenberg and Tirole (1995), Chapter 5.
} 


\begin{tabular}{|c|c|c|c|c|c|c|}
\hline \multirow{3}{*}{$\begin{array}{c}\text { (initial) } \\
\text { state }\end{array}$} & \multicolumn{4}{|c|}{ equilibrium strategies } & \multirow{2}{*}{\multicolumn{2}{|c|}{$\begin{array}{l}\text { equilibrium } \\
\text { payoffs }\end{array}$}} \\
\hline & \multicolumn{2}{|c|}{ firm 1} & \multicolumn{2}{|c|}{ firm 2} & & \\
\hline & in & out & in & out & firm 1 & firm 2 \\
\hline$(0,0)$ & 1.0000 & 0.0000 & 1.0000 & 0.0000 & 2.1111 & 2.1111 \\
\hline$(0,1)$ & 1.0000 & 0.0000 & 1.0000 & 0.0000 & 2.1111 & 2.3611 \\
\hline$(1,0)$ & 1.0000 & 0.0000 & 1.0000 & 0.0000 & 2.3611 & 2.1111 \\
\hline$(1,1)$ & 1.0000 & 0.0000 & 1.0000 & 0.0000 & 2.2222 & 2.2222 \\
\hline
\end{tabular}

Table 1: Stationary Cournot equilibrium with two active firms.

on this equilibrium for each possible initial state. Irrespective of whether initially neither firm, both firms, or one of the two firms is in the market, each will produce in the next period with probability 1 . There is only a slightly higher payoff for the firm that happened to be first incumbent, enjoying an instantaneous monopoly profit for a single period, when the initial market structure featured a monopoly.

Apart from this known equilibrium, however, a different stationary equilibrium turns out to exist, with a fundamentally different nature. Again for $\delta=0.95$, Table 2 displays its diagnostics. In this equilibrium, when none of the firms produces today, each will produce tomorrow with probability 0.9306 . This means that with probability $(1-0.9306)^{2}=0.0048$ no firm will enter, with probability 0.1292 exactly one - the probabilities are equally split over the two possible situations - and with probability 0.8660 two firms will be active tomorrow. Similarly, when in a certain period both firms are active, the next period all market structures can be reached with positive probability. However, once a firm is the only firm in the market today it will with certainty stop producing tomorrow, whereas the opponent firm that is not in the market today will be for sure one period later. The market will, in other words, display an alternating monopoly.

This dynamic stationary market equilibrium of alternating monopoly is, to our knowl-

\begin{tabular}{c||c|c|c|c||c|c}
\multicolumn{1}{c||}{\multirow{2}{*}{\begin{tabular}{c}
\multirow{2}{*}{ (initial) } \\
state
\end{tabular}}} & \multicolumn{3}{c||}{ equilibrium strategies } & \multicolumn{2}{c|}{$\begin{array}{c}\text { equilibrium } \\
\text { payoffs }\end{array}$} \\
\cline { 2 - 5 } & in & out & in & out & firm 1 & firm 2 \\
\hline$(0,0)$ & 0.9306 & 0.0694 & 0.9306 & 0.0694 & 2.3055 & 2.3055 \\
$(0,1)$ & 1.0000 & 0.0000 & 0.0000 & 1.0000 & 2.4359 & 2.5641 \\
$(1,0)$ & 0.0000 & 1.0000 & 1.0000 & 0.0000 & 2.5641 & 2.4359 \\
$(1,1)$ & 0.9306 & 0.0694 & 0.9306 & 0.0694 & 2.4166 & 2.4166
\end{tabular}

Table 2: Stationary equilibrium with alternating monopoly. 
edge, nowhere mentioned in the literature. Yet, one can think of examples of markets that seem indeed to display the type of production planning of the alternating monopolists, and that have the characteristics of our simple model. Television stations, for example, often alternate their prime shows, such as news services and sit-coms, intertemporally, so that they do not compete for viewers in the same time slot. Summer events, such as open air pop festivals, or local fancy fairs, are planned in different weeks of the season. And similarly, major sports games, particularly important matches such as finals, are planned not to overlap — both within one and the same sport, and among different sports. Likewise, it has been observed that large companies of relatively homogenous commodities that are only substantially differentiated by application of marketing methods, such as cola, tend to alternate their advertizing campaigns. None of these alternations in production involve any major entry or exit costs, if any at all. Next to geographical market division, therefore, intertemporal market division can well be a form of economic market division that reduces competition, and thus welfare.

\section{$4 \quad$ Is an Alternating Monopoly Likely?}

Having established its existence, the natural question to ask is how likely and robust the alternating monopoly equilibrium is. One approach to this question is to consider how long it takes before an alternating monopoly reveals itself, when both firms coordinate on that equilibrium. A first observation towards this is on the role of the discount factor $\delta$. For values of $\delta$ large enough, the alternating monopoly equilibrium exists and can be calculated. However, when firms become sufficiently impatient, it no longer pays to divide the market intertemporally, and the equilibrium disappears. This critical value of $\delta$ is equal to 0.80 , which corresponds to an interest rate of $25 \%$ per period. For all higher discount factors, an equilibrium industry structure characterized by an alternating monopoly can be found.

The likelihood of indeed observing an alternating monopoly can subsequently be studied as follows. Once the industry is in an alternating monopoly situation in a certain period, it will stay in that equilibrium forever - where at even periods the one firm is active and at odd periods the other. When the market structure is not a monopoly in a certain period, there is a positive probability that it will end up in a monopoly next period. Consequently, the cumulative probability of an alternating monopoly increases in time.

To see the speed with which this likelihood converges to one, consider the Markov process induced by the alternating monopoly equilibrium. Its transition probabilities are illustrated graphically in Figure 2-again for $\delta=0.95$. These state-transitions can be 


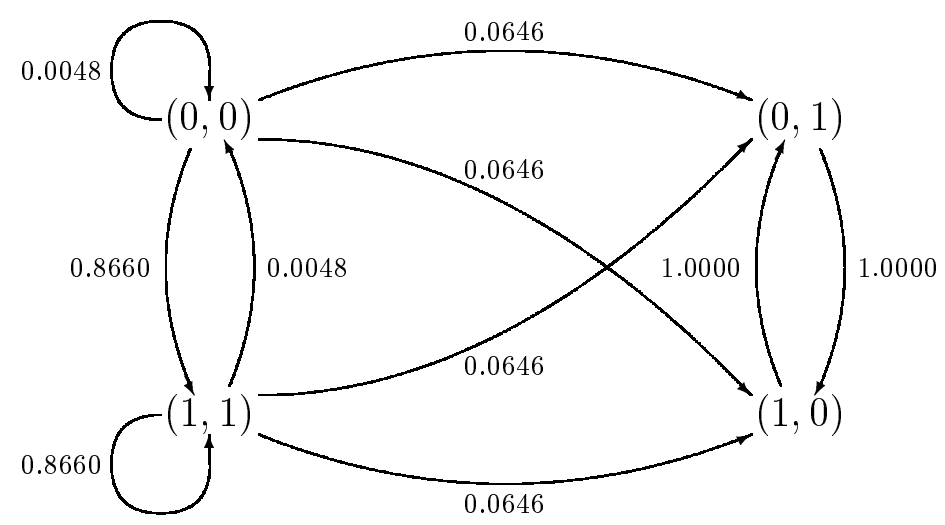

Figure 2: Transition-probabilities in market structure.

caught in the transition-matrix $P$ defined as

$$
P=\left[\begin{array}{llll}
0.0048 & 0.0646 & 0.0646 & 0.8660 \\
0.0000 & 0.0000 & 1.0000 & 0.0000 \\
0.0000 & 1.0000 & 0.0000 & 0.0000 \\
0.0048 & 0.0646 & 0.0646 & 0.8660
\end{array}\right] .
$$

The probability of having a certain market structure after two periods knowing the current market structure is given in the matrix $P^{2}$. When the current market structure is $\omega$, the probability that the market structure is $\bar{\omega}$ exactly $n$ periods later is given by the value of the matrix cell in row $\omega$ and column $\bar{\omega}$ of the matrix $P^{n}$. Regardless of what market structure is initially prevailing, therefore, the probability that an alternating monopoly is found after $n$ periods is at least equal to $P^{n}(1,2)+P^{n}(1,3) .{ }^{4}$

For all periods up to 50 we have computed these probabilities. The resulting data are displayed in Figure 3, for various values of $\delta$. Clearly, except for values of $\delta$ close to 0.80 , within some 50 periods the probability of an alternating monopoly rapidly converges to one. In fact, for $\delta=0.90$ the cumulative probability of an alternating monopoly is larger than 0.99 after exactly 50 periods. For $\delta=0.95$ this is the case after 34 periods, for $\delta=0.99$ after 27 periods, but even when $\delta=0.85$, it takes 98 periods for the cumulative probability of observing alternating monopoly to reach 0.99 .

There remains the question how reasonable it is to assume that coordination on the alternating monopoly equilibrium will happen. Towards answering this, it should be noted that in any game with multiple equilibria a similar question arises for each particular

4 Naturally, it is also at least equal to $P^{n}(4,2)+P^{n}(4,3)$. Moreover, computations showed that, in absence of entry costs, $P(1,2)=P(1,3)=P(4,2)=P(4,3)$. 


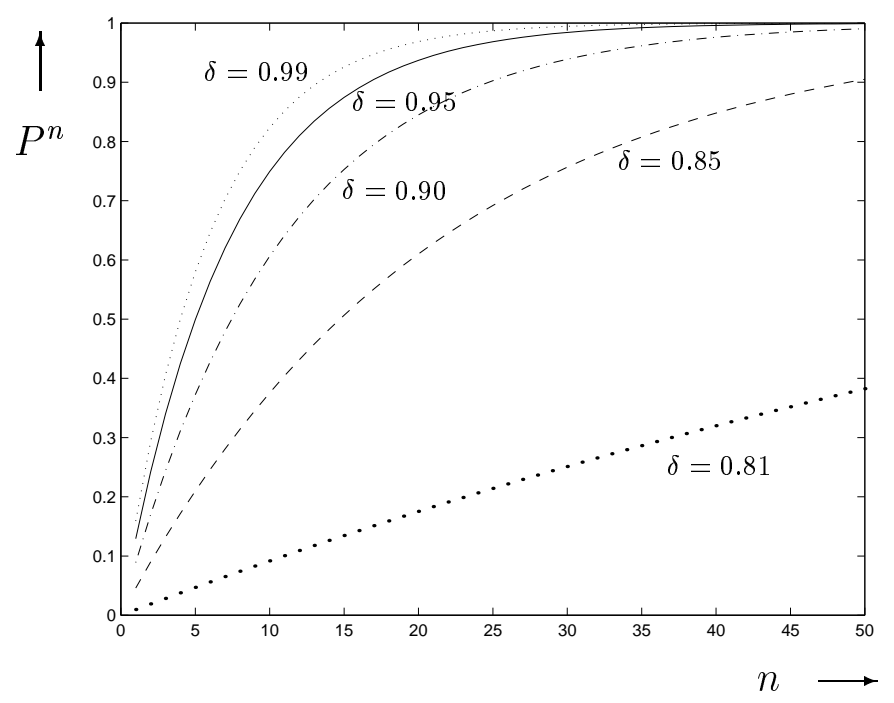

Figure 3: Speed of convergence to alternating monopoly for different discount factors.

equilibrium. Hence, for that matter, the alternating monopoly case is no less likely than the Cournot equilibrium. However, if anything, the alternating monopoly equilibrium is strictly more appealing to both firms, as they each make more profits, irrespective of the initial market structure. In fact, firms are able to extract close to the cartel profits, whereas a cartel is not sustainable as an equilibrium in this model.

In the case reported on above, where $\delta=0.95$, the total discounted profits of each firm in the alternating monopoly equilibrium is at least $8.5 \%$ higher than that had in the Cournot equilibrium. This is when both firms are initially in the market - compare to this end Table 1 and Table 2. The firm that is first in the market in the initial states with one firm so raises its payoff $15.5 \%$ over the Cournot profit. On average, the alternating monopoly equilibrium generates a discounted profit that is almost $12 \%$ higher than Cournot profits. For lower values of $\delta$ this difference becomes smaller, and it eventually converges to zero when $\delta$ gets very close to 0.80 . That is, for all values for which the alternating monopoly equilibrium exists, it is strictly payoff dominant.

\section{Concluding Thoughts}

We have reported on the possibility, so far unknown, that in the simplest of dynamic models of entry and exit, where none of the traditional assumptions used to show sustainable dominant positions, such as barriers to entry, simultaneous entry and punishment strategies are made, it is possible - and in fact reasonably likely - that an alternating monopoly 
arises, with payoffs that approach the cartel outcome, despite the fact that the market allows two firms to make profit when active, and does not sustain a cartel. Consequently also, consumer welfare is importantly harmed by the ability of firms to tacitly collude on this intertemporal market division. Production is decreased below, and prices increased above their duopoly levels, resulting in an increase in dead-weight loss. ${ }^{5}$ Hence, antitrust authorities should be wary of this possible tacit collusion - that, on top of being tacit, only unambiguously manifests itself in the long-run.

We believe the simplicity of the model strengthens the surprise of our result. Yet, in some directions it also calls for further inspection. To that end, we have performed the calculations for a version of the model in which firms do face (re-)entry costs. As these costs are to be incurred time and again in the alternating monopoly equilibrium, they are expected to rule out the equilibrium as a possibility when sufficiently high. It turns out that, with $\delta=0.95$, modest levels of entry costs of almost $8.5 \%$ of the instantaneous monopoly profits still sustain the alternating monopoly equilibrium as a profitable opportunity. ${ }^{6}$ With higher (re-)entry costs the alternating monopoly equilibrium no longer exists, leaving the Cournot equilibrium - which leads to the counterintuitive conclusion that slight barriers to entry can, in fact, support a relatively competitive environment. For all entry costs for which the alternating monopoly equilibrium exists, however, the latter is strictly payoff dominant.

The introduction of fixed costs, made in every period when producing, does not jeopardize our results either. That is, the alternating monopoly equilibrium exists for various non-specifically chosen parameter values. In fact, as fixed costs are incurred in either type of equilibrium, alternating monopoly or Cournot, they have no specific bearing on the issue at hand. Fixed costs do, however, open possibilities for interesting further research. We find, for example, specifications for which the Cournot equilibrium involves losses, whereas the alternating monopoly equilibrium is still sustainable - this is the case when discount factors and fixed costs are sufficiently high. The reason is that monopolists bear the fixed costs only every second period. The theory of natural monopoly seems, in other words, compatible with firms that share the market intertemporally.

Finally, of crucial importance to our result does seem to be the number of potential entrants. The two firm model studied here generates a two-period bifurcation. Yet, an $n$-firm extension would accordingly stretch this. When the number of firms increases, an

\footnotetext{
5 In fact, since in the linear model under consideration dead-weight loss is half of the total profits between the market parties, the discounted welfare loss left in alternating monopoly is also almost $12 \%$ higher on average than that in Cournot equilibrium.

6 That is, entry costs up to 0.0208 which is $8.33 \%$ of normalized profits-which are equal to 0.25 .
} 
alternating monopoly equilibrium would imply long, i.e., $n-1$, periods of being inactive for each firm, awaiting its turn to dominate the market every $n$th time. Obviously, this puts the patience of firms to the test, thereby narrowing the window of parameter values for which the alternating monopoly equilibrium exists - in the limit, when the number of firms goes to infinity, eventually closing it. It is, however, very well possible that a different type of equilibrium exists in an $n$-firm version of our model, namely one in which clusters of firms tacitly collude on sharing the market each period with only a restricted number of them. Over time, these clusters then alternate, again increasing profits at the expense of welfare. The existence and likelihood of these conjectured stationary equilibria are subject of further research.

\section{Appendix}

In general, a finite discounted stochastic game is given by

$$
\Gamma=\left\langle N, \Omega,\left\{S_{\omega}^{i}\right\}_{(i, \omega) \in N \times \Omega},\left\{u^{i}\right\}_{i \in N}, \pi, \delta\right\rangle .
$$

Here $N$ denotes the finite set of players, $\Omega$ denotes the finite set of states, and $S_{\omega}^{i}$ denotes the finite set of actions that player $i$ has at its disposal in state $\omega \in \Omega$. The instantaneous payoff to player $i$ in state $\omega$ when the players play $s_{\omega}=\left(s_{\omega}^{i}\right)_{i \in N}$ is given by $u^{i}\left(\omega, s_{\omega}\right)$. At the same time the probability of going to state $\bar{\omega}$ is given by the mapping $\pi$ and is equal to $\pi\left(\bar{\omega} \mid \omega, s_{\omega}\right)$. The players are allowed to randomize their strategies and their instantaneous payoff-function is extended to satisfy the expected utility property. The transition mapping is extended similarly. The players maximize the total stream of expected payoffs, where the future payoffs are discounted by discount factor $\delta \in(0,1)$.

The game proceeds as follows. All players $i$ select at the initial state $\omega^{0}$, simultaneously and independently of each other (possibly by a chance experiment), an action $\sigma_{\omega^{0}}^{i} \in \Delta\left(S_{\omega^{0}}^{i}\right)$. Then two things happen, both depending on the current state $\omega^{0}$ and the action choices $\sigma_{\omega^{0}}=\left(\sigma_{\omega^{0}}^{i}\right)_{i \in N}$,

(1) player $i$ earns $u^{i}\left(\omega^{0}, \sigma_{\omega^{0}}\right)$,

(2) the system jumps to the next state $\omega^{1}$ according to the outcome of the chance experiment given by $\pi\left(\cdot \mid \omega^{0}, \sigma_{\omega^{0}}\right)$.

Subsequently, in the next period, all players are informed about the previous actions chosen by the players, and of the new state $\omega^{1}$. The above procedure is repeated from the state $\omega^{1}$. 
Theorem 3.5 in Herings and Peeters (2000) states that a stationary strategy-tuple $\sigma$ is a stationary equilibrium if and only if it is part of a solution to

$u^{i}\left(\omega, \sigma_{\omega}^{-i}, s_{\omega j}^{i}\right)+\delta \cdot \sum_{\bar{\omega} \in \Omega} \pi\left(\bar{\omega} \mid \omega, \sigma_{\omega}^{-i}, s_{\omega j}^{i}\right) \mu_{\bar{\omega}}^{i}+\lambda_{\omega j}^{i}-\mu_{\omega}^{i}=0, \quad\left(s_{\omega j}^{i} \in S_{\omega}^{i}, \omega \in \Omega, i \in N\right)$,

$\lambda_{\omega j}^{i} \geq 0, \quad \sigma_{\omega j}^{i} \geq 0, \quad \lambda_{\omega j}^{i} \sigma_{\omega j}^{i}=0, \quad\left(s_{\omega j}^{i} \in S_{\omega}^{i}, \omega \in \Omega, i \in N\right)$,

$\sum_{s_{\omega j}^{i} \in S_{\omega}^{i}} \sigma_{\omega j}^{i}-1=0, \quad(\omega \in \Omega, i \in N)$.

Here, $\lambda_{\omega j}^{i}$ is the shadowprice of playing strategy $s_{\omega j}^{i}$, i.e., the disutility of a marginal increase in the probability $\sigma_{\omega j}^{i}$ by which pure strategy $s_{\omega j}^{i}$ is played at the initial period, and $\mu_{\omega}^{i}$ is the expected payoff of player $i$ when the initial state is $\omega, \sigma^{-i}$ is played by its opponents, and player $i$ chooses a best response against $\sigma^{-i}$.

\section{References}

1. Bain, J.S. (1956), Barriers to New Competition, Harvard University Press, Cambridge MA.

2. Baumol, W.J., J.C. Panzar and R.D. Willig (1982), Contestable Markets and the Theory of Industry Structure, Harcourt Brace Jovanich, New York.

3. Dasgupta, P. and J. Stiglitz (1988), "Potential Competition, Actual Competition, and Economic Welfare," European Economic Review, 32, 569-577.

4. Dixit, A. and C. Shapiro (1986), "Entry Dynamics and Mixed Strategies," in: L.G. Thomas (ed.), Strategic Planning, Lexington Books, Lexington MA, pp. 63-79.

5. Fink, A.M. (1964), "Equilibrium in a Stochastic n-Person Game," Journal of Science of Hiroshima University Series A-I, 28, 89-93.

6. Fudenberg, D. and J. Tirole (1995), Game Theory, MIT Press, Cambridge MA.

7. Haller H. and R. Lagunoff (2000), "Genericity and Markovian Behavior in Stochastic Games," Econometrica, 68, 1231-1248.

8. Herings, P.J.J. and R.J.A.P. Peeters (2000), "Stationary Equilibria in Stochastic Games: Structure, Selection, and Computation," Meteor Research Memorandum 00/031, University of Maastricht, Maastricht.

9. Judd, K.L. (1997), "Computational Economics and Economic Theory: Substitutes or Complements?," Journal of Economic Dynamics and Control, 21, 907-943. 
10. Judd, K.L. (1998), Numerical Methods in Economics, MIT Press, Cambridge MA.

11. Maskin, E. and J. Tirole (2001), "Markov Perfect Equilibrium, I: Observable Actions," Journal of Economic Theory, 100, 191-219.

12. Neyman, A. and S. Sorin (2001), Stochastic Games, Proceedings of the 1999 NATO Summer Institute on Stochastic Games held at Stony Brook, forthcoming.

13. Selten, R. (1978), "The Chain Store Paradox," Theory and Decision, 9, pp.127-159

14. Shapley, L.S. (1953), "Stochastic Games," Proceedings of the National Academy of Sciences, 39, 1095-1100.

15. Sobel, M.J. (1971), "Non-Cooperative Stochastic Games," The Annals of Mathematical Statistics, 42, 1930-1935.

16. Stiglitz, J. (1981), "Potential Competition May Lower Welfare," American Economic Review, 71, 184-189.

17. Takahashi, M. (1964), "Equilibrium points of stochastic, noncooperative $n$-person games," Journal of Science of Hiroshima University Series A-I, 28, 95-99.

18. Vives, X. (1988), "Sequential Entry, Industry Structure and Welfare," European Economic Review, 32, 1671-1687.

19. Waldman, M. (1991), "The Role of Multiple Potential Entrants/Sequential Entry in Noncooperative Entry Deterrence," Rand Journal of Economics, 22, 446-453.

20. Watson, L.T., S.C. Billups and A.P. Morgan (1987), "Hompack: A Suite of Codes for Globally Convergent Homotopy Algorithms," ACM Transactions on Mathematical Software, 13, 281-310. 